\title{
viruses
}

ISSN 1999-4915

www.mdpi.com/journal/viruses

Correction

\section{Correction: Forrester, N.L.; Coffey, L.L.; Weaver, S.C. Arboviral Bottlenecks and Challenges to Maintaining Diversity and Fitness during Mosquito Transmission. Viruses 2014, 6, 3991-4004}

\section{Naomi L. Forrester ${ }^{1, *}$, Lark L. Coffey ${ }^{2}$ and Scott C. Weaver ${ }^{1}$}

1 Institute for Human Infections and Immunity, Department of Pathology, University of Texas

Medical Branch, Galveston, TX 77555, USA; E-Mail: sweaver@utmb.edu

2 Center for Vectorborne Diseases and Department of Pathology, Microbiology and Immunology,

School of Veterinary Medicine, University of California, Davis, CA 95616, USA;

E-Mail: 1coffey@ucdavis.edu

* Author to whom correspondence should be addressed; E-Mail: naforres@utmb.edu;

Tel.: +1-409-266-6911; Fax: +1-409-747-2429.

External Editor: Rollie Clem

Received: 5 November 2014 / Accepted: 6 November 2014 / Published: 14 November 2014

In the original manuscript, Forrester, N.L.; Coffey, L.L.; Weaver, S.C. Arboviral Bottlenecks and Challenges to Maintaining Diversity and Fitness during Mosquito Transmission. Viruses 2014, 6, 3991-4004, Figure 1 contains an error, the third bottle was absent from the figure:

The correct figure should be:

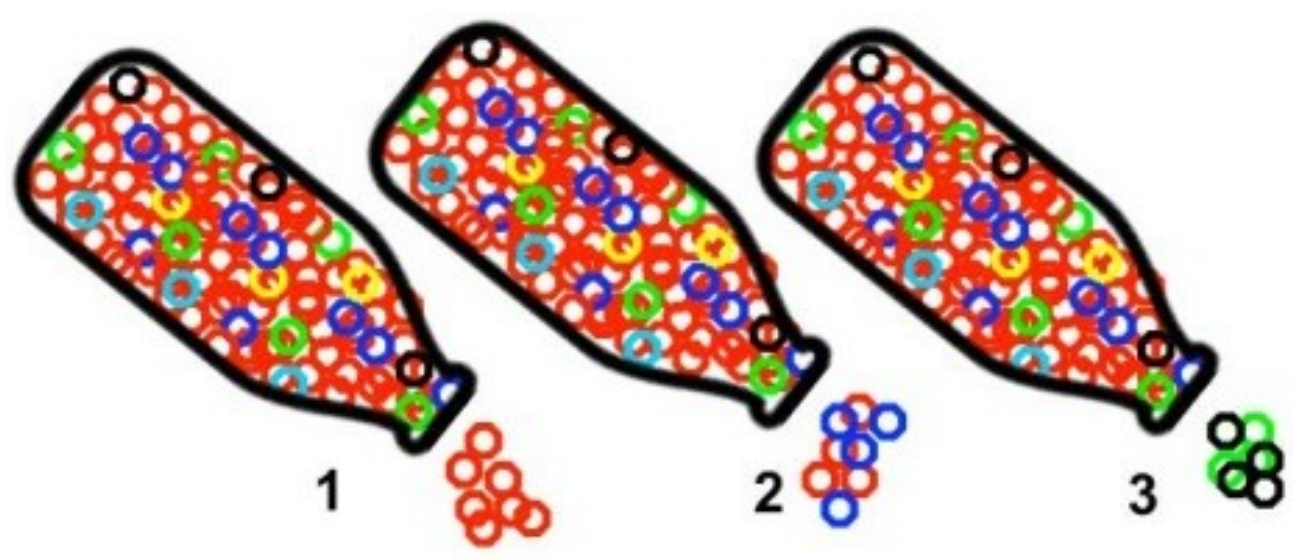


Figure 1. Effects of a bottleneck on virus populations, where virus variants are shown as colored circles: (1) Only the largest subpopulation is maintained after the bottleneck and viral variation decreases; (2) Virus variability decreases but a small amount of viral diversity is retained; and (3) Virus population diversity changes significantly due to random selection of small subpopulations and the dominant sequence is not perpetuated.

\section{References and Notes}

1. Forrester, N.L.; Coffey, L.L.; Weaver, S.C. Arboviral Bottlenecks and Challenges to Maintaining Diversity and Fitness during Mosquito Transmission. Viruses 2014, 6, 3991-4004.

(C) 2014 by the authors; licensee MDPI, Basel, Switzerland. This article is an open access article distributed under the terms and conditions of the Creative Commons Attribution license (http://creativecommons.org/licenses/by/4.0/). 